\title{
La Mancomunidad provincial Interinsular de Santa Cruz de Tenerife
}

Pretender hablar de algo que se relacione con el régimen local de las Islas Canarias, sin resaltar la labor realizada en este aspecto por mi ilustre compañero don Leopoldo de la Rosa Olivera, Secretario del Organismo objeto de este comentario, sería silenciar un trabajo que por su importancia y trascendencia, constituye una verdadera obra de consulta para todo aquel que intente bucear sobre el origen y desarrollo de la administración local en el Archipiélago.

Más de dos años de búsqueda infatigable entre legajos y pergaminos, aparte de una preparación personal indiscutible, dan a la obra citada un destacado valor, pues su autor, partiendo de la época del descubrimiento de las islas en el siglo xiv, llega en sus investigaciones hasta nuestros días.

No se pretende, por tanto, en estas líneas, emular la obra de tan insigne compañero, cosa que, por otra parte, resultaría imposible para mí, hasta el punto de que - con permiso de su autor- he tenido necesidad de buscar en su obra los antecedentes precisos para poder orientarme sobre la razón de existir que pudiera tener el Organismo que nos ocupa.

Las vicisitudes que pasó la Diputación de Canarias, desde su creación, en 1813, hasta que desaparece definitivamente con el Estatuto Provincial de 1925, quedan amplia y documentalmente expuestas en la obra citada. Estas vicisitudes destacan desde el primer momento una intensa rivalidad entre Tenerife y Gran Canaria, rivalidad que intentó resolver el citado Estatuto, suprimiendo la Diputación y creando una Mancomunidad Interinsular obligatoria, que aunque de reducido ámbito, no solucionaba tampoco el problema, pues las disputas sobre cuáles habrian de ser las atribuciones y servicios del nuevo orga- 
nismo creado, se producían de igual forma que con la extinguida Diputación.

El Real decreto de 21 de septiembre de 1927, dividió el Archipiélago en dos provincias: la de Tenerife (compuesta por las islas de Tenerife, La Palma, La Gomera y El Hierro) y la de Las Palmas (en la que se incluían las islas de Gran Canaria, Lanzarote, Fuerteventura y los islotes de la Alegranza, Roque del Este, Roque del Oeste, Graciosa, Montaña Clara y Lobos). Para adaptar el título VI del libro I del Estatuto Provincial a la nueva división del Archipiélago, se publica el Real decreto Ley de 8 de mayo de 1928, que dispone la subsistencia de los Cabildos, y crea dos Mancomunidades forzosas radicantes cada una de ellas en la capitalidad de la respectiva provincia.

Al amparo de ésta última disposición, la Mancomunidad de Tenerife confeccionó su Reglamento orgánico, aprobado por Real decreto de 7 de agosto de 1929, no haciéndolo así la de Las Palmas, que no asumió servicio alguno, funcionando en el propio Cabildo y con personal de esta Corporación.

Saltando determinados atisbos de regionalismo aparecidos al discutirse la Constitución de 1931, y al presentarse a las Cortes en 1934 el proyecto de Ley Provincial, que no llegaron a prosperar, es lo cierto que se publica la Ley de Bases de Administración Local de 17 de julio de 1945, sin que la organización y funcionamiento de la Mancomunidad de Tenerife haya sufrido variación.

En las disposiciones finales de la citada Ley, se respeta la subsistencia de Cabildos y Mancomunidades, y por ello consideramos oportuno destacar aquí la necesidad y conveniencia de robustecer la hacienda de estas últimas Corporaciones, si se aspira a que cumplan con holgura los fines para que fueron creadas.

En efecto, la Mancomunidad no se configura como un organismo amorfo, carente de personalidad, sin vida propia, y supeditado a la mezquindad de uno o varios Cabildos que pugnan por su desaparición. Ello es incompatible con la representación que ostenta y los fines que se le han asignado. Sin embargo, la supeditación de su hacienda casi a la exclusiva apor- 
tación de los Cabildos, viene produciendo en la práctica una continua traba a su normal desenvolvimiento.

Sabido es que el Presupuesto de Ingresos de la Mancomunidad se nutre principalmente con las aportaciones que realizan los Cabildos, del cinco por ciento de sus respectivos Presupuestos de Ingresos, deduciendo de éstos determinadas partidas. Esta aportación que tiene el carácter de forzosa, no cubre ni aproximadamente las necesidades normales que exige su funcionamiento. $\mathrm{Y}$ aquí precisamente es donde empiezan las dificultades.

El Reglamento orgánico de la Mancomunidad, ya citado, previniendo este caso, establecía en su art. 51 la posibilidad de ampliar la aportación forzosa señalada, pero para ello -dice«...será siempre necesaria la previa y expresa conformidad de los cuatro Cabildos de la Provincian.

$\mathrm{Y}$ nosotros nos atrevemos a preguntar: ¿Qué interés pueden tener los Cabildos en prestar esta conformidad a una ampliación de la cifra que forzosamente aportan, cuando es lo cierto que no se avienen a reconocer la necesidad y razón de ser que tiene la Corporación que la pide?

Adviértase entonces cuál es la curiosa posición de un Organismo, representativo de una Provincia, que tiene que mendigar la solución de su déficit y, por consiguiente, la aprobación de su Presupuesto a unas Entidades que jerárquicamente son inferiores.

Consciente la Comisión Gestora sustitutiva de la Excelentísima Mancomunidad de Tenerife de todos estos problemas, interesó de la Superioridad, en propuesta debidamente argumentada, la revisión de los preceptos vigentes, por los inconvenientes que en la práctica plantea su aplicación, solicitando una modificación de la cuantía de la aportación forzosa, que sería cifrada en el déficit inicial del Presupuesto, y previniendo una aportación extraordinaria, que tendría, en su caso, el carácter de imposición de exacción, lo que siempre representa una garantía para los Cabildos.

Creemos todavía insuficiente la solución, si se piensa en un Organismo independiente, que no tenga que recurrir a conti- 
nuas compensaciones, que no siempre cubren la cantidad adeudada, por las excepciones que a estos efectos señala el Reglamento orgánico tantas veces citado. Por ello confiamos que sin perjuicio de aceptarse las modificaciones propuestas, se tenga en cuenta esta Corporación, a los efectos de la distribución, en su caso del excedente del Fondo de Corporaciones Locales, a que alude el art. 213 de la vigente "Ordenación Provisional de las Haciendas Locales".

Hoy la Mancomunidad sostiene entre otros servicios un Sanatorio Psiquiátrico, para atender al cual, naturalmente, no le basta con la aportación forzosa de los Cabildos y los ingresos propios de la Corporación (de escasa importancia), por lo que se hace preciso siempre la aportación extraordinaria para enjugar el déficit presupuestario, aportación que siempre resulta difícil conseguir, pues los Cabildos retrasan su aprobación y originan un entorpecimiento que se traduce en que, por ejemplo, el Presupuesto del año 1946 no haya podido entrar en vigor hasta el 26 de marzo último.

Como todo comentario basado exclusivamente en cifras suele resultar árido, quiero limitarme a destacar aquí las necesidades que a la Mancomunidad le origina el sostenimiento del Sanatorio citado, y por ellas fácilmente se puede formar una idea del problema planteado y de la conveniencia de solucionarlo.

Ingresos efectivos de la Mancomunidad, excepción hecha de la aportación extraordinaria durante el año 1945.

Aportaciones forzosas de los Cabildos $434.050,66$ ptas

Donativos al Sanatorio 144,90 ) Importe de medicamentos facilitados a enfermos. Pendiente de cobro por el mismo concepto ...... Importe de estancias en el Sanatorio ... ... ... ... Pendiente de cobro por el mismo concepto ... ... Participación del 5 por 100 sobre cuotas rústicas. Pendiente de cobro por el mismo concepto ...... Participación en el arbitrio municipal sobre traviesas en frontones y carreras de galgos ... ...... 
Los gastos presupuestados para sostenimiento del Sanatorio importaron en el mismo año la cantidad de 923.848 pesesetas, es decir: que con los ingresos propios de la Corporación y las aportaciones forzosas de los Cabildos, no se llegó a cubrir el mínimo de necesidades que reclamaba el Sanatorio, por lo que fué preciso interesar una aportación extraordinaria que en el año 1945 rebasó el importe de la forzosa al alcanzar la cifra de 531.946,82 pesetas, para con ella atender a completar dicha obligación y cubrir el resto del Presupuesto de Gastos, que por otra parte hubo necesidad de fijar en cuantía modestísima, ante la pugna que representaba obtener de los Cabildos la previa y expresa conformidad.

Esto por lo que se refiere al funcionamiento exclusivo del Manicomio, y sin pretensiones de mejoras en el citado servicio, pues ello representaría un considerable aumento de las aportaciones insulares, difícil de conseguir al menos mientras persista el actual estado de cosas. Por otra parte, la posibilidad de recurrir a un Presupuesto Extraordinario queda descartada salvo que se arbitrasen recursos especialmente afectos a dicha finalidad, lo que en principio resulta bastante dificil, y no siendo así, como las fuentes de ingreso serían las mismas, surgirían los mismos inconvenientes.

También merece destacarse la situación de inferioridad en que se encuentran los funcionarios que prestan sus servicios a la Mancomunidad, pues dándose el caso de que todos los organismos insulares conceden mejoras a sus empleados, consistentes en pluses por carestía de vida y pagas extraordinarias, es lo cierto que en la Mancomunidad no pueden atenderse estas necesidades con la justicia que el caso requiere, porque toda mejora supone aumentos del Presupuesto de Gastos, y ello supone a su vez, aumentos en las aportaciones de los Cabildos, que tropieza siempre con la negativa de estos, resultando entonces que funcionarios y plazas de igual categoría, cuando no de superior, no disfrutan de los mismos beneficios.

Si la aportación forzosa de los Cabildos, que se fijó en el cinco por ciento, resulta insuficiente, $y$ de hecho se viene abonando a esta Corporación una cantidad extraordinaria que ya 
hemos visto supera en ocasiones a la normal, ello viene a fortalecer las pretensiones de la Mancomunidad, para que la aportación forzosa abarque el déficit inicial de su Presupuesto, sin perjuicio de procurarle otros ingresos que la independicen.

Por todo ello, y considerando la necesidad incuestionable de su subsistencia como Corporación, por cuanto de unidad y representación hay en ella, aspectos que han perdurado más de un siglo, pese a las diferentes transformaciones de que ha sido objeto, y además porque el sostenimiento de determinados servicios traería, de fraccionarse, su lógico debilitamiento, o en otro caso la absorción por el Cabildo más fuerte del servicio de que se tratase, con menoscabo de los intereses de los demás, confiamos que estudiado el problema con la serenidad que el caso requiere, habrá de encontrarse fórmula adecuada que permita a la Mancomunidad desenvolverse con independencia, cesando en la vida lánguida y llena de zozobras económicas que en la actualidad viene arrastrando.

\section{José Llorca Gisbert}

Interventor de Fondos de la Excma. Mancomunidad Interinsular de Tenerife. 